\title{
Enhancing Dopamine Detection Using Glassy Carbon Electrode Modified with Graphene Oxide, Nickel and Gold Nanoparticles
}

\author{
Chedia Ben Ali Hassine, ${ }^{1}$ Hamza Kahri, ${ }^{1,2, z}$ and Houcine Barhoumi ${ }^{1}$ \\ ${ }^{1}$ Laboratory of Interfaces and Advanced Materials, Faculty of Sciences, University of Monastir, Tunisia \\ ${ }^{2}$ Faculty of Science, Department of Chemistry, Bilkent University, 06800 Ankara, Turkey
}

A novel and an easy method was developed to fabricate non-enzymatic electrochemical sensor for sensitive detection of dopamine (DA). A composite material contains graphene oxide and nickel nanoparticles was deposited on a glassy carbon electrode (GCE) surface by cyclic voltammetry. Then, gold particles were loaded on the surface of the resulting material via galvanic replacement method in order to obtain $\mathrm{Ni}-\mathrm{Au}$ bimetallic nanoparticles combined with the electrodeposited graphene oxide (EG). The electrochemical behavior and the structure of the obtained electrode were characterized using scanning electron microscopy, cyclic voltammetry and impedance spectroscopy. The response of the modified electrode for DA detection is linear in the range from $2 \times$ $10^{-7}$ to $10^{-4} \mathrm{M}$, the sensitivity is $0.641 \mathrm{~A} \mathrm{M}^{-1}$ and the detection limits is $10^{-7} \mathrm{M}$. As well, it showed a high selectivity in the presence of Uric acid (UA), Ascorbic acid (AA) and glucose. Due to its low-cost, an easy process and great performance, this GCE/ EG-Ni-Au(NPs) electrode can be a good candidate for the fabrication of non-enzymatic dopamine sensor.

(C) 2020 The Electrochemical Society ("ECS”). Published on behalf of ECS by IOP Publishing Limited. [DOI: 10.1149/1945-7111/ ab6971]

Manuscript submitted July 31, 2019; revised manuscript received November 20, 2019. Published January 21, 2020.

Dopamine (DA) act as a neurotransmitter and have several roles in the function of renal, central nervous and hormonal systems. ${ }^{1}$ The abnormal concentration of dopamine in the human body can lead to several mental diseases. ${ }^{2}$ Therefore, the selective and sensitive detection of DA are an urgent need. To obtain more performant sensor, several techniques have been applied for the detection of DA such as fluorescence spectrometry, mass spectrometry and electrochemical techniques. ${ }^{3,4}$ Surrounded by those techniques, electrochemical methods have attracted great interest due to the facile oxidation of DA electrochemically. ${ }^{5-7}$ Electrochemical methods draw more attention because of their low-cost, quick response and ease of use. ${ }^{8}$ Nowadays increasing interest is being paid on the development of sensitive devices for DA detection. ${ }^{9-15}$ In order to have more sensitive sensor and larger linearity domain for dopamine detection, various carbon materials have been employed to modify electrodes surfaces such as carbon nanotubes, ${ }^{16}$ boron-doped diamond, ${ }^{17}$ carbon nanofibers ${ }^{18}$ and graphite. ${ }^{19}$ Recently, graphene oxide (GO) have been reported to be effective for electrochemical sensors. Outstanding to its $2 \mathrm{D}$-dimensional structure, GO has many unexpected properties, where electrons behave like massless relativistic particles, resulting in the observation of novel electronic properties such as the quantum Hall effect ${ }^{20}$ and transport by means of relativistic Dirac fermions. ${ }^{21}$ Electrochemical method for selective detection of dopamine was reported by a group of researches based on gold-nanoparticles-cyclodextrin-graphene-modified electrode by square wave voltammetry. ${ }^{22}$ The sensing film was fabricated with in situ thermal reduction of graphene oxide and $\mathrm{HAuCl}_{4}$ with cyclodextrin (CD) in alkaline aqueous solution. ${ }^{22}$ To have good analytical performances of the sensor, the method of graphene deposition on the electrode surface is an important step. Graphene films are usually deposited using simple methods like drop-casting but it was demonstrated that using this method the thickness of the film cannot be controlled. ${ }^{23}$ Recently, electrochemical methods are used in order to have thin layers on the electrode surface. $^{23}$ In addition, the use of metallic nanoparticles (NPs) can enhance the analytical performances of sensors. Ni NPs have attracted much interest in the field of electrochemistry due to their original properties such as an ease of synthesis and low cost. Nickel nanoparticles have been used in electrode modification due of its extraordinary catalytic activities and high conductivities. ${ }^{24,25}$ For example, nickel nanoparticles were used as an efficient electrocatalyst for the detection of synthetic antioxidant propyl gallate [26]. In the present work, we report a facile and a low cost preparation of

${ }^{\mathrm{z}}$ E-mail: hamza.kahri@bilkent.edu.tr nanocomposite EG/Ni-Au (NPs) modified glassy carbon electrode (GCE) by two steps: (i) an electrochemical deposition of $\mathrm{Ni}$ nanoparticles and graphene oxide on the glassy carbon electrode, (ii) a simple immersion of the obtained material in an aqueous solution of $\mathrm{HAuCl}_{4}$. The electrochemical activity of $\mathrm{Ni}-\mathrm{Au} / \mathrm{EG}$ modified GCE was investigated and its selective detection toward DA was studied in the terny mixture of glucose, ascorbic acid (AA) and uric acid (UA).

\section{Experimental}

Chemicals and materials.-Ferricyanide $\left(\mathrm{K}_{4} \mathrm{Fe}(\mathrm{CN})_{6}\right)$ and ferrocyanide $\left(\mathrm{K}_{3} \mathrm{Fe}(\mathrm{CN})_{6}\right)$, Potassium monohydrogen phosphate $\left(\mathrm{K}_{2} \mathrm{HPO}_{4}\right)$ and Potassium dihydrogen phosphate were purchased from Fluka. Commercial nanopowder of nickel with an average particle size $<100 \mathrm{~nm}$, graphene oxide (GO) dispersion in $\mathrm{H}_{2} \mathrm{O}$ $\left(4 \mathrm{mg} \mathrm{ml}^{-1}\right)$ and Chloroauric acid tetrahydrate $\left(\mathrm{HAuCl}_{4}\right)$ were purchased from Sigma-Aldrich. Aqueous solutions were prepared using ultrapure water (Millipore milli-Q, resistivity $>18.2 \mathrm{M} \Omega \mathrm{cm}$ ).

Instruments and measurements.-Surface morphology characterization was performed using a scanning electron microscope JSM 5100 from JEOL with carbon screen printed electrode. Experimental electrochemical measurements were carried out with electrochemical cell containing three electrodes a glassy carbon electrode (GCE) with a geometric area of $0.07 \mathrm{~cm}^{2}$, a platinum wire as a counter electrode and an $\mathrm{Ag} / \mathrm{AgCl} /$ (sat. $\mathrm{KCl}$ ) electrode as a reference. The cyclic voltammetry $(\mathrm{CV})$ and square wave voltammetry (SWV) were investigated using a potentiostat (DY200 POT Eco-chimie). An Autolab PGSTAT 320 N potentiostat was used for impedance spectroscopy spectra measurements controlled by a computer with a software (NOVA 1.5) for data analysis. Square wave measurements were recorded from 0 to $0.5 \mathrm{~V}$ with a step potential of $4 \mathrm{mV}$, an amplitude of $40 \mathrm{mV}$ and a frequency of $10 \mathrm{~Hz}$ in the presence of phosphate buffer solution (PBS) $0.1 \mathrm{M}(\mathrm{pH}=6)$.

Electrode preparation and modification procedure.-The electrode surface modification was done using many steps shown in Fig. 1. The first step is cleaning the electrode surface in order to remove impurities and to have reproducible results. The working electrode (GCE) was polished using $\mathrm{Al}_{2} \mathrm{O}_{3}(1 \mu \mathrm{m})$ water slurry using a polishing cloth and then the electrode surface was rinsed with pure water. After, the electrode was sonicated in acetone for 10 min and rinsed with pure water. The freshly cleaned GCE was electrochemically activated in an electrochemical cell containing 

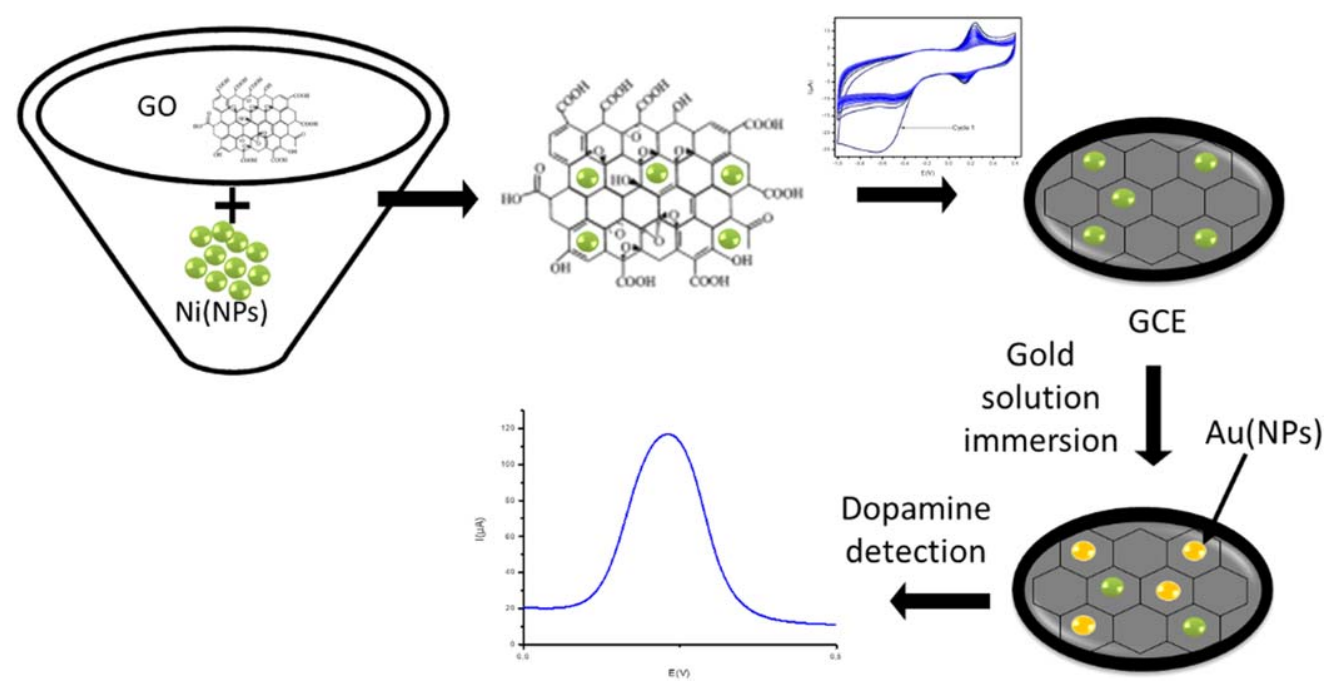

Figure 1. Schematic illustration of the different steps involved in the fabrication of the modified glassy carbon electrode.

$\mathrm{NaOH}\left(0.5 \mathrm{~mol} \cdot \mathrm{1}^{-1}\right)$ with a repetitive cyclic potential sweeps in the range of 0.6 to $1.2 \mathrm{~V}$ at a scan rate of $50 \mathrm{mV} \cdot \mathrm{s}^{-1}$. The modification of the electrode was done by cyclic voltammetry in an electrochemical cell $(10 \mathrm{ml})$ containing graphene oxide $\left(1 \mathrm{mg} \mathrm{ml}^{-1}\right)$ and nickel nanoparticles (Ni(NPs) $\left(1 \mathrm{mg} \mathrm{ml}^{-1}\right)$ by 15 cycles at a scan rate of $20 \mathrm{mV} \cdot \mathrm{s}^{-1}$ as shown in voltammograms reported in Fig. 2. Then the electrode was immersed in an aqueous solution of $2.10^{-4} \mathrm{M} \mathrm{HAuCl}_{4}$ for $30 \mathrm{~min}$. For details about the $\mathrm{Au}$ adhesion on the electrode surface containing the $\mathrm{Ni}(\mathrm{NPs})$, the reader is invited to refer to our previous publication. ${ }^{26}$

\section{Results and Discussion}

Characterization of the modified glassy carbon electrode.-The morphology of the modified electrodes was examined by scanning electron microscopy (SEM) in order to verify the homogeneity of those surfaces and the adhesion of the deposited materials. Figure 3 illustrates the surface morphologies of modified electrodes by SEM. Figure 3a represents the SEM for bare screenprinted carbon electrode and it was taken as a reference, it is clear that the morphology of the electrode surface changes after electrodeposition of GO, which confirms the formation of electrodeposited graphene (EG) layer on the GC surface. Figure 3c shows a SEM image of EG $+\mathrm{Ni}(\mathrm{NPs})$ layer adsorbed on the electrode surface. Figure $3 \mathrm{~d}$ indicates that $\mathrm{Ni}-\mathrm{Au}$ bimetallic nanoparticles have larger surface area and they consist of small spherical particles which are highly dispersed on the surface. The SEM images reveal that the best electrode is GCE/EG-Ni-Au(NPs). The modified electrodes were also characterized using two electrochemical methods: cyclic voltammetry and impedance spectroscopy. To characterize the formation of the deposited layer on the working electrode surface, cyclic voltammograms were recorded in a three electrode cell containing the redox active compounds: $\mathrm{Fe}(\mathrm{CN})_{6}{ }^{3-} / \mathrm{Fe}(\mathrm{CN})_{6}{ }^{4-}$ in $0.1 \mathrm{M} \mathrm{PBS}$ at $\mathrm{pH}=6$. Figure 4 shows the cyclic voltammograms before and after modification of the GC electrode. The voltammograms recorded in redox system present a reversible behavior at the bare and modified electrodes with a small peak separation for the bare electrode $\Delta \mathrm{E}=89 \mathrm{mV}$ and a larger peak separation for the modified electrode $\Delta \mathrm{E}=129 \mathrm{mV}$ for the GCE/EG-Ni(NPs) and $\Delta \mathrm{E}=146 \mathrm{mV}$ GCE/EG-Ni-Au (NPs). As it is shown in Figs. $4 b$ and $4 c$, after the modification of the GC electrode by GCE/EG-Ni(NPs) and GCE/EG-Ni-Au(NPs) an increase in the peak current is observed due to the effect of $\mathrm{Ni}-\mathrm{Au}$ bimetallic nanoparticles. Due to their synergistic effects $\mathrm{Ni}$ and Au NPs can enhance the oxidation of electroactive molecules which serve as efficient species for highly sensitive

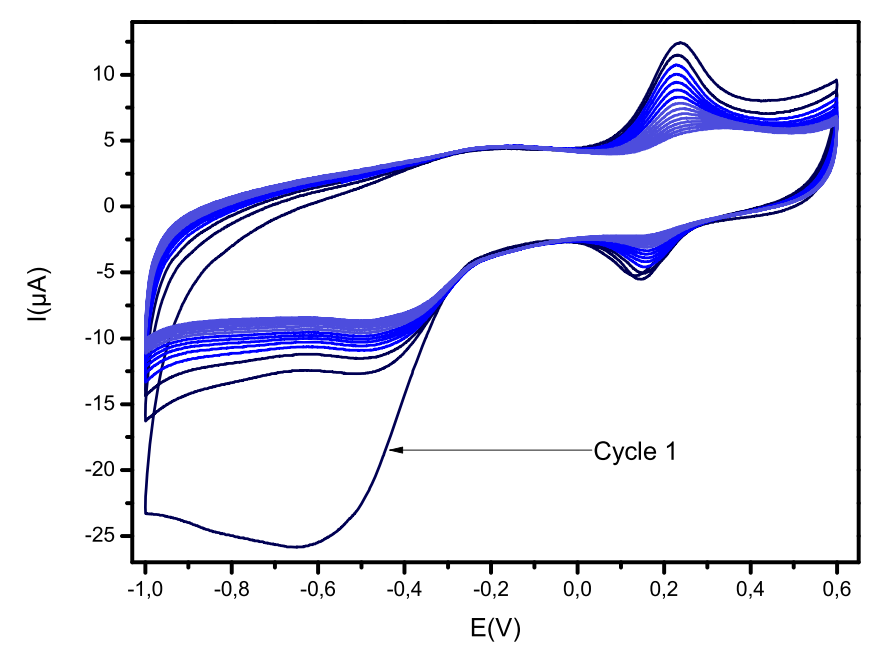

Figure 2. Electrochemical deposition of GO/Ni on GCE using cyclic voltammetry for 15 cycles at $20 \mathrm{mV} \mathrm{s}^{-1}$.

electrochemical sensing applications ${ }^{27}$ (Table I). The characterization of the deposited layer on the GC electrode was also performed by impedance spectroscopy method at an applied potential of $215 \mathrm{mV}$ in the presence of redox compounds in $0.1 \mathrm{M} \mathrm{KCl}$ as shown in Fig. 5. Impedance spectra were fitted to equivalent circuits using NOVA 1.5 and the obtained results are given in Table II. Based on the adopted equivalent circuits (Fig. 5) many parameters were estimated such as the solution resistance (Rs), the charge transfer resistance (Rct), the constant phase element (CPE) and the diffusion impedance (W) (Table II). The nyquist plots of the bare GC electrode represents at low frequency a straight line with a small semi-circle at high frequency region. A decrease in the semi-circle is observed after modification of the electrode surface due to the effect of the deposited layer which is

Table I. Electrochemical parameters of bare and modified GC electrode of the cyclic voltamogramms for $1.0 \mathrm{mM}$

$\mathrm{Fe}(\mathrm{CN})_{6}{ }^{3-} / \mathrm{Fe}(\mathrm{CN})_{6}{ }^{4-}$ solution (in $\left.0.1 \mathrm{M} \mathrm{KCl}\right)$.

\begin{tabular}{lccc} 
Electrodes & $\mathrm{I}_{\mathrm{a}}(\mu \mathrm{A})$ & $\mathrm{I}_{\mathrm{c}}(\mu \mathrm{A})$ & $\Delta \mathrm{E}(\mathrm{V})$ \\
\hline Bare GCE & 50.35 & 50.20 & 89 \\
GCE/EG-Ni(NPs) & 58.86 & 58.87 & 129 \\
GCE/EG-Ni-Au(NPs) & 69.66 & 69.34 & 146
\end{tabular}




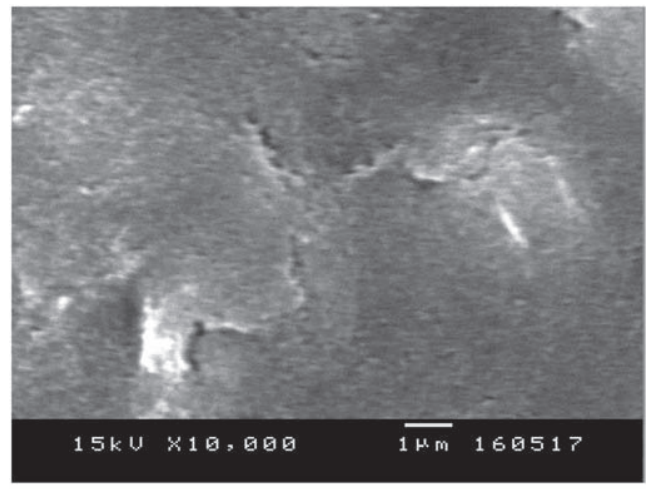

(a)

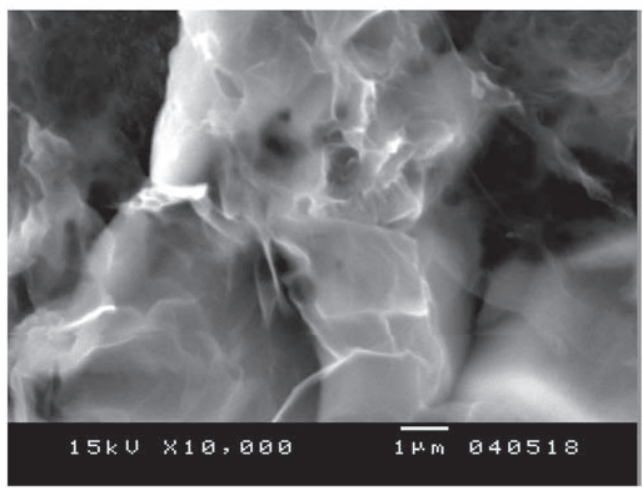

(c)

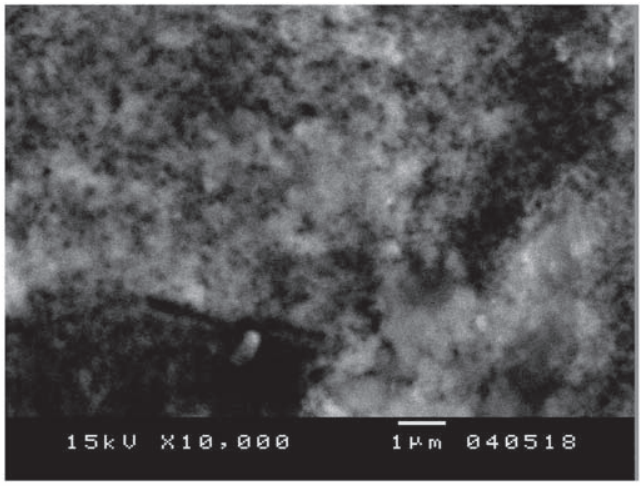

(b)

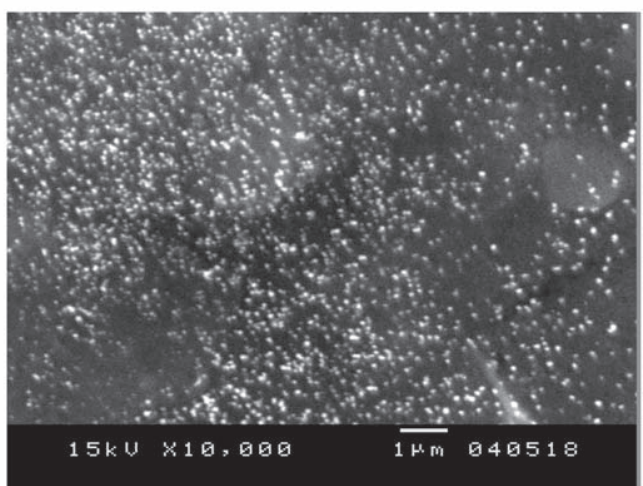

(d)

Figure 3. Scanning electron micrographs, (a) bare screen-printed carbon electrode (SPCE), (b) GCE/EG, (c) GCE/EG-Ni(NPs), (d) GCE/EG-Ni-Au(NPs). Resolution of $1 \mu \mathrm{m}$, magnification of 10.000 and accelerating potential of $15.0 \mathrm{kV}$ were used.

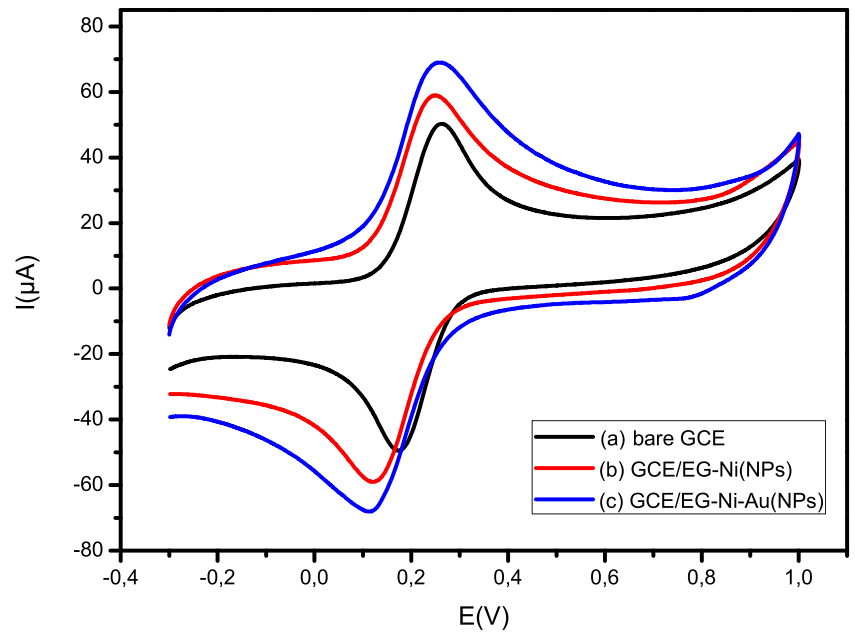

Figure 4. Cyclic voltammograms of $1.0 \mathrm{mM}$ of $\mathrm{Fe}(\mathrm{CN})_{6}{ }^{3-} / \mathrm{Fe}(\mathrm{CN})_{6}{ }^{4-}$ in 0,1 M PBS pH 6 of (a) bare GCE, (b) GCE/EG-Ni(NPs), (c) GCE/EG-Ni-Au (NPs). At potential sweep rate of $100 \mathrm{mV} \mathrm{s}^{-1} \mathrm{vs} \mathrm{Ag} / \mathrm{AgCl} /(\mathrm{sat} . \mathrm{KCl})$. related to lower charge transfer resistance (Rct) than it was estimated for the bare GC. This indicates the excellent electrical conductivity of the deposited layer.

Cyclic voltammetry behavior of dopamine at modified GCE.The CV responses of DA at bare electrode, GCE/EG-Ni(NPs) and GCE/EG-Ni-Au(NPs) are shown in Fig. 6. It is clear that GCE/EG$\mathrm{Ni}-\mathrm{Au}(\mathrm{NPs})$ shows a higher oxidation peak current if it compared with bare electrode and GCE/EG-Ni(NPs). The increase of the peak current after the modification of the electrode with $\mathrm{Au}(\mathrm{NPs})$ could be attributed to the excellent electrical conductivity of the $\mathrm{Au}(\mathrm{NPs}){ }^{28}$

Effect of $\boldsymbol{p H}$.-The effect of $\mathrm{pH}$ on the electrochemical responses of GCE/EG-Ni-Au(NPs) in the detection of DA has been investigated. As shown in Fig. 7, the anodic peak potentials of DA shift negatively with the increase of $\mathrm{pH}$ from 2.0 to 10.0 . The anodic peak currents increase as the $\mathrm{pH}$ value increases up to 6.0 and then a slight decrease with continuing increase of $\mathrm{pH}$ is observed Fig. 8b. Therefore, 0.1 M PBS solution with $\mathrm{pH}=6.0$ is chosen for our research. The relationship between $\mathrm{pH}$ and anodic peak potential was further studied. Figure 8 a display that the

Table II. Electrochemical parameters of bare and modified GC electrode obtained from the analysis of impedance data with the equivalent circuits.

\begin{tabular}{lccrr} 
Electrodes & $\mathrm{R}_{\mathrm{S}}(\Omega)$ & $\mathrm{CPE}(\mu \mathrm{F})$ & $\mathrm{R}_{\mathrm{tc}}(\Omega)$ & $\mathrm{W}(\mu \mathrm{F})$ \\
\hline Bare GCE & 169.88 & 12.2 & 642.04 & 529 \\
GCE/EG-Ni(NPs) & 246.96 & 8.96 & 524.53 & 0.0522 \\
GCE/EG-Ni-Au(NPs) & 179.86 & 12.3 & 448.36 & 664 \\
\end{tabular}



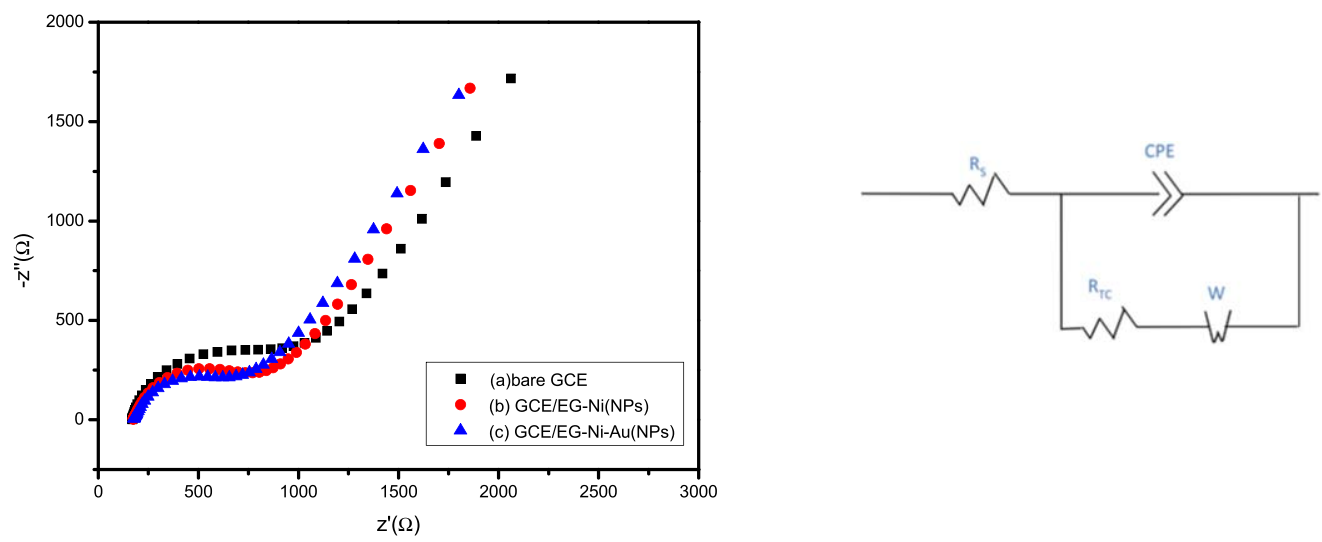

Figure 5. Nyquist plots of $1.0 \mathrm{mM} \mathrm{Fe}(\mathrm{CN})_{6}{ }^{3-} / \mathrm{Fe}(\mathrm{CN})_{6}{ }^{4-}$ solution in $0.1 \mathrm{M}$ of $\mathrm{KCl}$ of (a) bare GCE, (b) GCE/EG-Ni(NPs), (c) GCE/EG-Ni-Au(NPs). Frequency range is from 0.05 to $75,000 \mathrm{~Hz}$, the modulation amplitude is $10 \mathrm{mV}$, working electrode potential is $215 \mathrm{mV}$ and the Equivalent circuit applied for calculations $[(\mathrm{R}(\mathrm{Q}[\mathrm{RW}]]$.

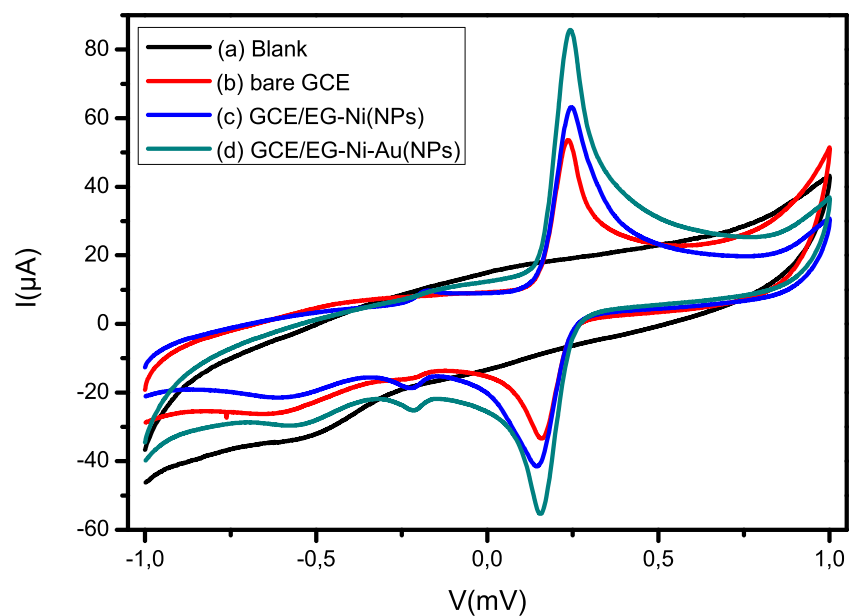

Figure 6. Cyclic voltammograms of modified electrodes performed with dopamine $1 \mathrm{mM}$ in $\mathrm{PBS} \mathrm{pH}=6$. At potential sweep rate of $100 \mathrm{mV} \mathrm{s}^{-1} \mathrm{vs}$ $\mathrm{Ag} / \mathrm{AgCl} /($ sat. $\mathrm{KCl}$ ). (a) Blank (modified electrode in PBS) (b) bare GCE, (c) GCE/EG-Ni(NPs), (d) GCE/EG-Ni-Au(NPs).

anodic peak potentials $\left(\mathrm{E}_{\mathrm{a}}\right)$ of DA have a good linear relationship with the solution $\mathrm{pH}$ in the range from 2.0 to 8.0. The linear regression equations of $\mathrm{DA}$ is $\mathrm{E}_{\mathrm{a}}(\mathrm{DA})=-0.065 \mathrm{pH}+0.641$, the slope of 65 (DA) represented in equations is close to the

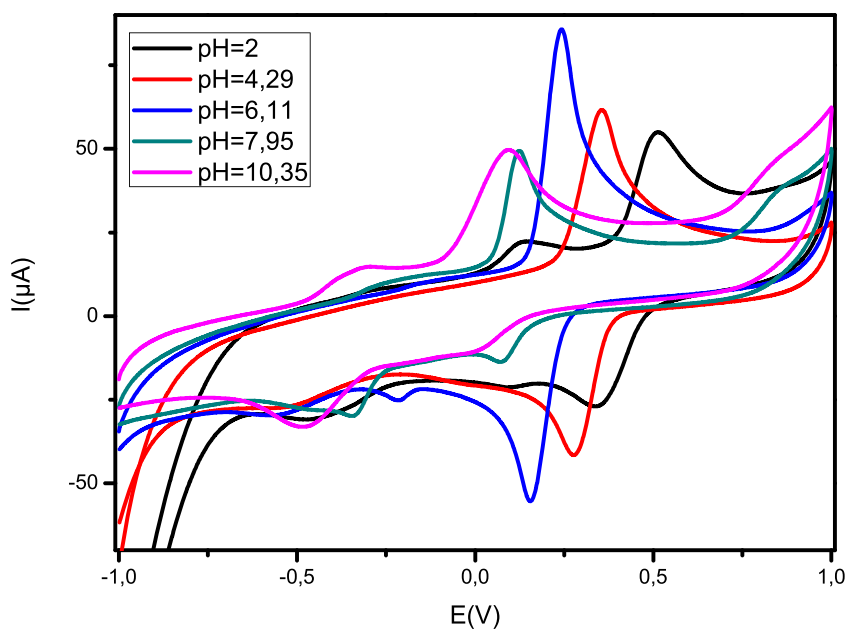

Figure 7. Cyclic voltammograms of dopamine $1 \mathrm{mM}$ in $0.1 \mathrm{M}$ PBS buffer solution at various $\mathrm{pHs}$ at $\mathrm{GCE} / \mathrm{EG}-\mathrm{Ni}-\mathrm{Au}(\mathrm{NPs})$. The scan rate is $100 \mathrm{mV} \mathrm{s}^{-1}$ vs $\mathrm{Ag} / \mathrm{AgCl} /($ sat. $\mathrm{KCl}$ ).

anticipated Nernstian value defined as $59 \mathrm{mV}$ per pH at $25^{\circ} \mathrm{C}$, indicating that the number of electron and transferred proton involved in the electrochemical reaction is equal. The reaction is exhibited as follow ${ }^{29}$ :

Table III. Comparison of the proposed modified GCE with other electrochemistry methods in the detection of dopamine.

Methods

Gold nanoparticles-cyclodextrin-graphene-modified electrode with SWV

Graphene-diamond electrode with DPV

GO/GCE with DPV

Electrochemically reduced GO/GCE with DPV

$\mathrm{rGO} / \mathrm{AuNPs}$ with DPV

$\mathrm{Fe}_{3} \mathrm{O}_{4} / \mathrm{r}-\mathrm{GO} / \mathrm{GCE}$

$\mathrm{Au} / \mathrm{rGO} / \mathrm{GCE}$

Colorimetric based on salt-induced AuNP aggregation

Colorimetric based on the aggregation of AuNPs induced by copper ions

Electrochemiluminescence sensor CdSe quantum dots

Fluorescence method based on BSA-Au NCs quenching

GCE/EG-Ni-Au(NPs) with SWV

\section{Linearity}

$0.5-150 \mu \mathrm{M}$

$5 \mu \mathrm{M}-2 \mathrm{mM}$

$1.0-15 \mu \mathrm{M}$

$0.5-60 \mu \mathrm{M}$

$1-60 \mu \mathrm{M}$

$0.4-3.5 \mu \mathrm{M}$

6.8-41 M $\mu \mathrm{M}$

$33 \mathrm{nM}-3.33 \mathrm{mM}$

$0.5-10 \mu \mathrm{M}$

$0.20-12 \mu \mathrm{M}$

$0-6 \mathrm{nM}$

$0.2-100 \mu \mathrm{M}$
Detection limit

$0.15 \mu \mathrm{M}$

$200 \mathrm{mM}$

$0.27 \mu \mathrm{M}$

$0.50 \mu \mathrm{M}$

$20 \mu \mathrm{M}$

$0.08 \mu \mathrm{M}$

$1.4 \mu \mathrm{M}$

$33 \mathrm{nM}$

$200 \mathrm{nM}$

$0.5 \mu \mathrm{M}$

$0.622 \mathrm{nM}$

$0.1 \mu \mathrm{M}$
References

22

22
30

31

32

33

34

35

36

37

38

39

This work

GO: graphene oxide.

rGO: reduced graphene oxide. 


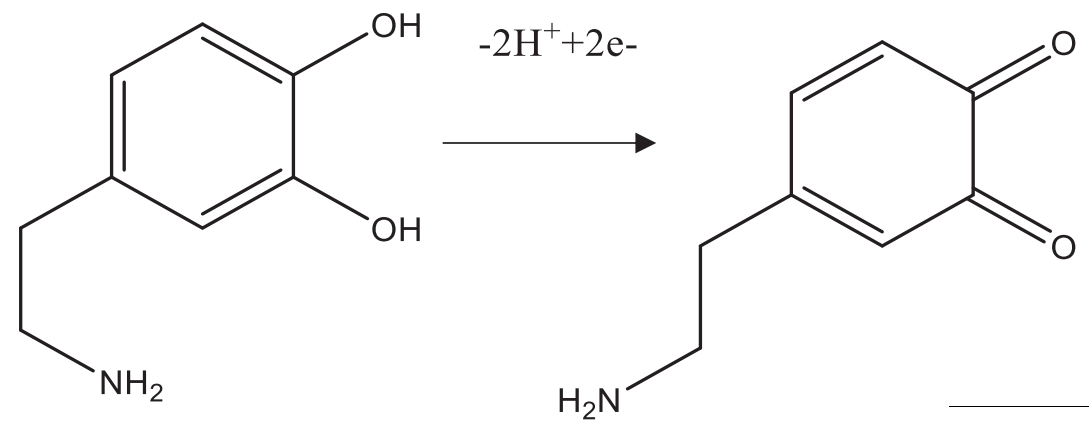

Electrochemical detection of $\boldsymbol{D A} .-\mathrm{n}$ order to investigate the electrode performance for dopamine sensing, the Square wave voltammetry (SWV) method was carried out using GCE/EG-Ni-Au (NPs) modified electrode. As shown in Fig. 9, the characteristic peak current of dopamine in $0.1 \mathrm{M}$ PBS increases with the increase of the added concentrations from $1 \mathrm{nM}$ to $1 \mathrm{mM}$. As depicted in Fig. 9, the oxidation peak currents shows an enhancement with the increase of

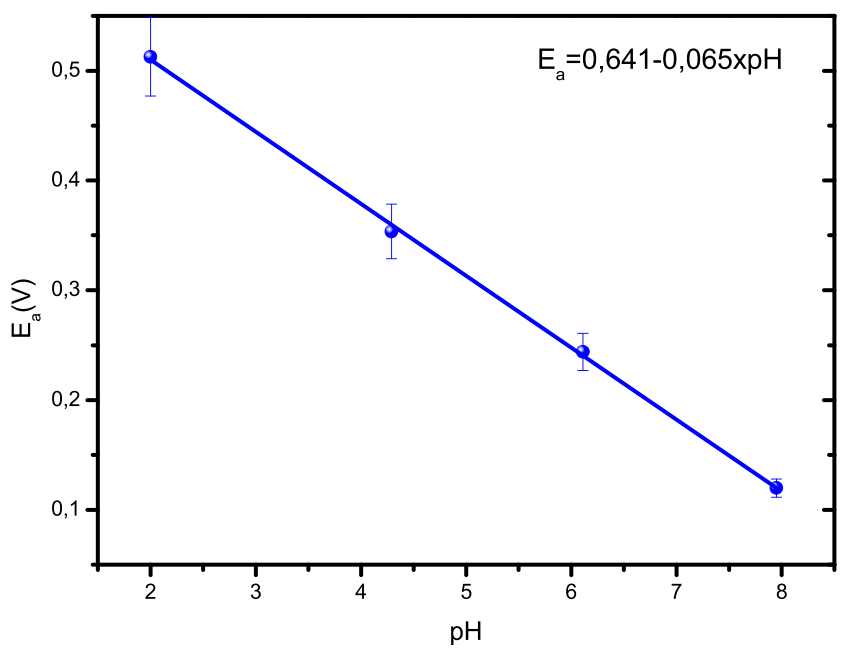

(A)

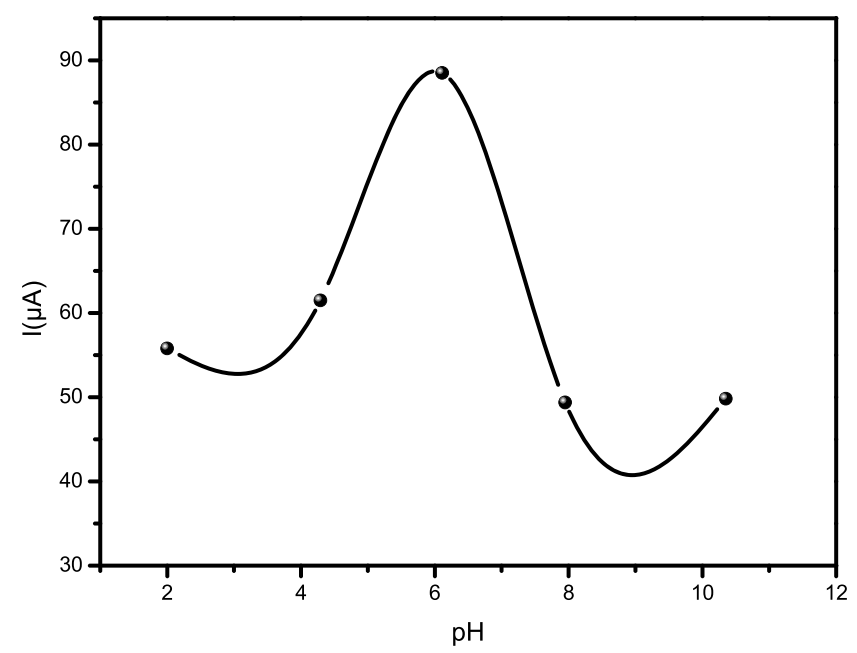

(B)

Figure 8. (A) Anodic peak potentials against $\mathrm{pH}$ and (B) Relationship between the anodic peak current and $\mathrm{pH}$ values in the presence of $1 \mathrm{mM}$ DA.
DA concentrations. The relationship of the peak current as a function of dopamine concentration is plotted in Fig. 10 and it shows a good linearity with a linear equation:

$$
\begin{aligned}
I(A)= & 0.641 \times x+1,559 E-5\left(R^{2}=0,9872\right) \\
& \left(\text { Linear range: } 2 \times 10^{-7}-10^{-4} \mathrm{M}\right)
\end{aligned}
$$

The detection limits of DA is found to be $0.1 \mu \mathrm{M}$. Various nanocomposites based non-enzymatic dopamine sensors are summarized in Table III. Compared with others reported nanocomposites based dopamine sensors, the GCE/EG-Ni-Au(NPs) electrode shows comparable sensitivity and linear range. Also, if we compare between our elaborated method and the standard methods like Colorimetric methods for detection of dopamine (Table III) we can consider that our sensor has a good response. After the step of DA detection, the modified electrode can be regenerated after $45 \mathrm{~min}$ immersion in deionized water under stirring (Fig. 11). It is clear that all the DA molecules were removed from the surface of the modified electrode. The influence of various substances like UA, AA and glucose as potential interference compounds on the determination of dopamine was studied under the optimum conditions with $10^{-5} \mathrm{M} \mathrm{DA}$ at $\mathrm{pH}=6.0$. The results given in Fig. 12 show that the peak current of DA is not significantly affected by the studied potential interfering species. Therefore, ascorbic acid showed interference in determination of DA if its concentration is 100 times higher than DA concentration. Human serum samples were used for analysis of DA. For evaluation of the analytical performance of our sensor, a known amount of dopamine was added to real samples and results are depicted in Table IV. The appreciable found and recovery results revealing that our modified GCE is promising for the determination of DA present in real samples.

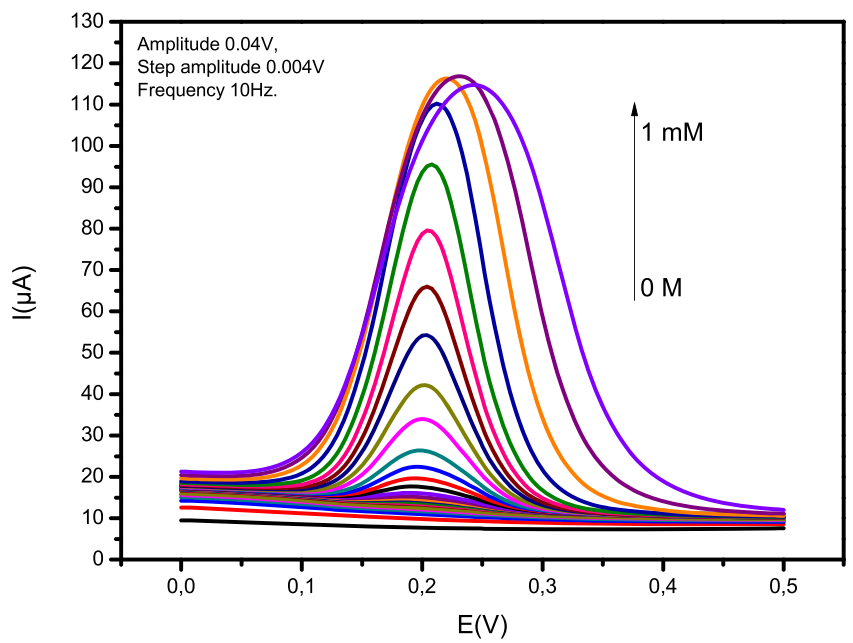

Figure 9. Anodic square wave voltammograms spectra of GCE/EG-Ni-Au (NPs) in the presence of dopamine in PBS $(0.1 \mathrm{M}) \mathrm{pH}=6$. Amplitude $0.04 \mathrm{~V}$, Step amplitude $0.004 \mathrm{~V}$ and frequency $10 \mathrm{~Hz}$. 

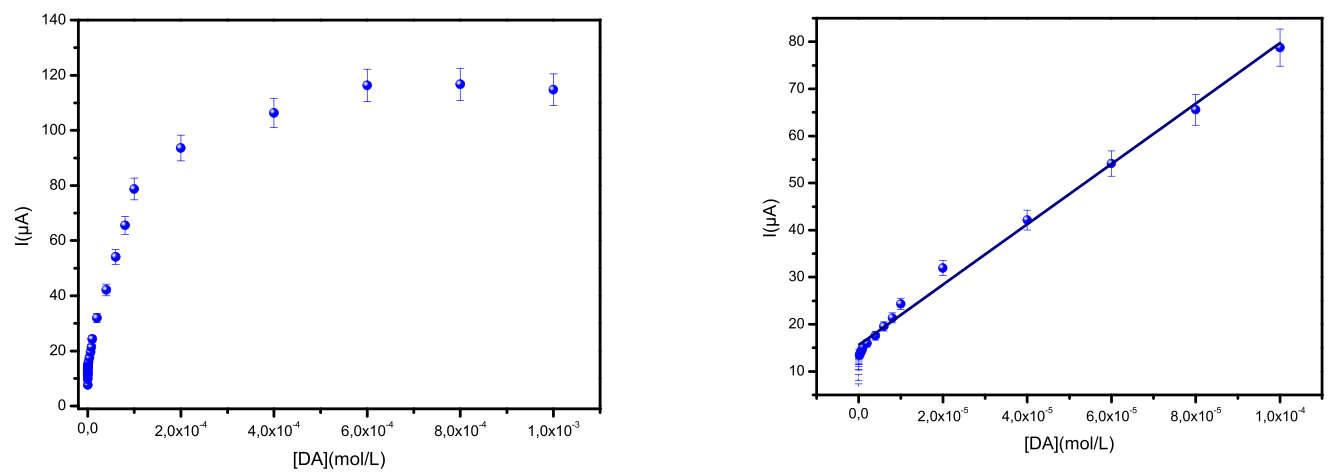

$$
I(A)=0.641 \times x+1,559 E-5\left(R^{2}=0,9872\right)
$$

Figure 10. PLots of oxidation peak currents vs the concentrations of DA from 0 to $10^{-3} \mathrm{M}$.

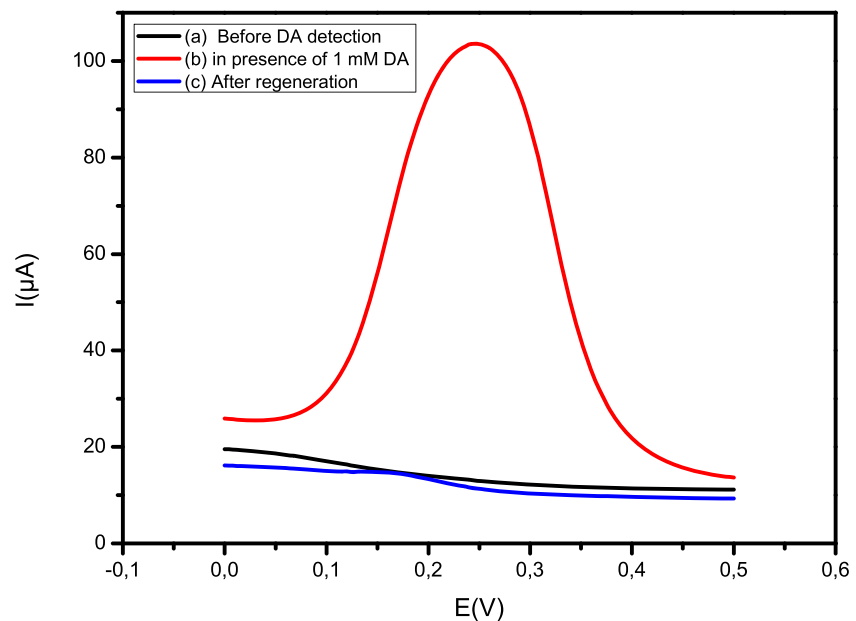

Figure 11. Square Wave Voltammetry of a modified glassy carbon electrode in phosphate buffer $\mathrm{pH}=6$, before and after regeneration with deionized water solution. (a) Before DA detection, (b) in presence of $10^{-3} \mathrm{M} \mathrm{DA}$ and (c) After regeneration.

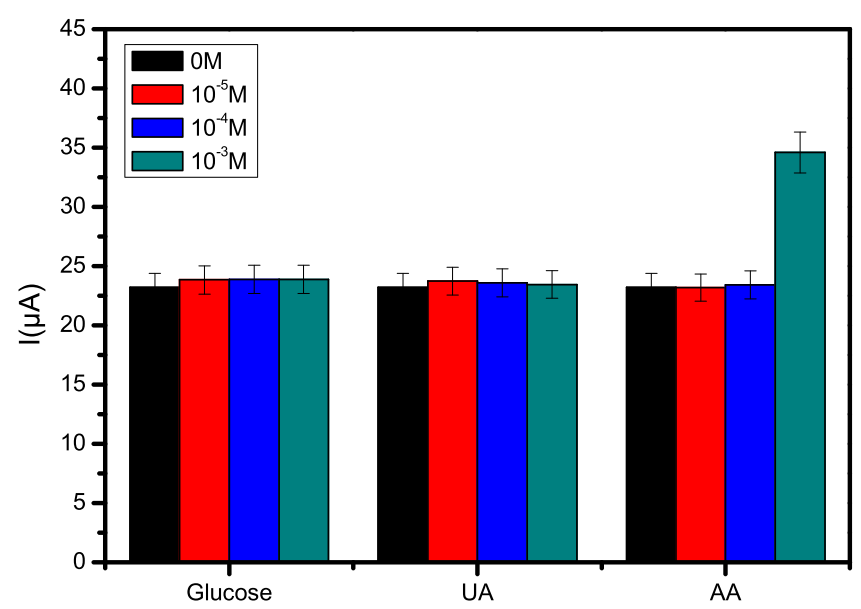

Figure 12. Effect of interfering molecules UA, AA and glucose in presence of $10^{-5} \mathrm{M}$ dopamine (various concentrations of interfering species from down to up; $10^{-5}-10^{-3} \mathrm{M}$ ). Supporting electrolyte was $0.1 \mathrm{M}$ phosphate buffer $(\mathrm{pH}=6)$.

$\begin{aligned} & \text { Table IV. Application of the proposed method for determination of } \\ & \text { dopamine. }\end{aligned}$
$\begin{aligned} & \text { Human serum } \\ & \text { samples }\end{aligned}$
$\begin{array}{lcccc}\text { Samples 1 } & \text { Added } & \text { Found } & \text { RSD\% } & \text { Recovery\% } \\ \text { Samples 2 } & 5 \times 10^{-6} & 0.98 \times 10^{-6} & 2.79 & 98 \\ \text { Samples 3 } & 10^{-4} & 4.8 \times 10^{-5} & 1.08 & 96 \\ & & 0.98 \times 10^{-4} & 2.33 & 98\end{array}$

\section{Conclusions}

In this work, a highly performing detection of dopamine compound was performed using modified glassy carbon electrode with EG INi-Au(NPs). The modified electrode with EG-Ni-Au(NPs) showed better electrochemical properties than bare and EG-Ni(NPS), in terms of reducing peak-to-peak separation and intensity of the peak for DA characterized by a reversible behavior. The SWV analysis using a portable instrument highlighted the advantages of using EG-Ni-Au (NPs), this sensor is able to detect DA with high sensitivity and large linear range.

\section{Acknowledgments}

Authors would like to acknowledge BRF-Tunisia project (No. 12Mag088), and the Ministry of Higher Education and Scientific Research of Tunisia (LR11ES55). H.K thanks to the Scientific and Technological Research Council of Turkey (TUBITAK) for the fellowship.

\section{References}

1. M. L Heien, A. S Khan, J. L Ariansen, J. F Cheer, P. E Phillips, K. M Wassum, and R. M Wightman, "Real-time measurement of dopamine fluctuations after cocaine in the brain of behaving rats." Proc. Natl Acad. Sci. USA, 102, 10023 (2005).

2. D. Li, P. C. Sham, M. J. Owen, and L. He, "Meta-analysis shows significant association between dopamine system genes and attention deficit hyperactivity disorder (ADHD)." Hum. Mol. Genet., 15, 2276 (2006).

3. D. Rao, X. Zhang, Q. Sheng, and J. Zheng, "Highly improved sensing of dopamine by using glassy carbon electrode modified with $\mathrm{MnO}_{2}$ graphene oxide." Microchim. Acta, 183, 2597 (2016).

4. S. Palanisamy, S. Ku, and S. M Chen, "Dopamine sensor based on a glassy carbon electrode modified with a reduced graphene oxide and palladium nanoparticles composite." Microchim. Acta, 180, 1037 (2013).

5. W. L Yeh, Y. R Kuo, and S. H Cheng, "Voltammetry and flow-injection amperometry for indirect determination of dopamine." Electrochem. Commun., 10, 66 (2008).

6. Z. Jia, J. Liu, and Y. Shen, "Fabrication of a template-synthesized gold nanorodmodified electrode for the detection of dopamine in the presence of ascorbic acid." Electrochem. Commun., 9, 2739 (2007). 
7. N. Jia, Z. Wang, G. Yang, H. Shen, and L. Zhu, "Electrochemical properties of ordered mesoporous carbon and its electroanalytical application for selective determination of dopamine." Electrochem. Commun., 9, 233 (2007)

8. W. H. Zhou, H. H. Wang, W. T. Li, X. C. Guo, D. X. Kou, Z. J. Zhou, Y. N. Meng, Q. W. Tian, and S. X. Wu, "Gold nanoparticles sensitized ZNO nanorods arrays for dopamine electrochemical sensing." J. Electrochem. Soc., 165, G3001 (2018).

9. H. J. Lee and H. Kim, "Graphite felt coated with dopamine-derived nitrogen-doped carbon as a positive electrode for a vanadium redox flow battery." J. Electrochem Soc., 162, A1675 (2015).

10. A. G. Zestos and B. J. Venton, "Communication-carbon nanotube fiber microelectrodes for high temporal measurements of dopamine." J. Electrochem. Soc. 165, G3071 (2018)

11. S. Demuru and H. Deligianni, "Surface PEDOT:nafion coatings for enhanced dopamine, serotonin and adenosine sensing." J. Electrochem. Soc., 164, G129 (2017).

12. M. Jarczewska, S. Reddy Sheelam, R. Ziołkowski, and A. Gorski, "Label-free electrochemical DNA aptasensor for the detection of dopamine." J. Electrochem. Soc., 163 (2016)

13. Y. Baikeli, X. Mamat, N. Yalikun, Y. Wang, M. Qiao, and G. Hu, "Simultaneous determination of dopamine and uric acid using glassy carbon electrode modified with almond-shell-based nanoporous carbon." J. Electrochem. Soc., 166, B1171 (2019).

14. N. R. Devi, T. H. V. Kumar, and A. K. Sundramoorthy, "Electrochemically exfoliated carbon quantum dots modified electrodes for detection of dopamine neurotransmitter." J. Electrochem. Soc., 165, G3112 (2018).

15. C. Duan and J. Zheng, "Bimetallic MOF-based enzyme-free sensor for highly sensitive and selective detection of dopamine." J. Electrochem. Soc., 166 (2019) B942.

16. I. Mustafa, I. Lopez, H. Younes, R. Agung, S. Rashid, and A. Almheir, "Fabrication of freestanding sheets of multiwalled carbon nanotubes (Buckypapers) for vanadium redox flow batteries and effects of fabrication variables on electrochemical performance." Electrochim. Acta, 230, 222 (2017).

17. A. Fujishima, T. N. Rao, E. Popa, B. V. Sarada, I. Yagi, and D. A. Tryk, "Electroanalysis of dopamine and NADH at conductive diamond electrodes." J. Electroanal. Chem., 473, 179 (1999).

18. S. Gupta, A. Yadav, and N. Verma, "Simultaneous $\mathrm{Cr}(\mathrm{VI})$ reduction and bioelectricity generation using microbial fuel cell based on alumina-nickel nanoparticles-dispersed carbon nanofiber electrode." Chem. Eng. J., 307, 729 (2017).

19. P. Ramesh, G. S. Suresh, and S. Sampath "Selective determination of dopamine using unmodified, exfoliated graphite electrodes." J. Electroanal. Chem., 561, 173 (2004).

20. Y. B. Zhang, Y. Tan, H. L. Stormer, and P. Kim, "Experimental observation of the quantum Hall effect and Berry's phase in graphene." Nature, 438, 201 (2005).

21. K. S. Novoselov, A. K. Geim, S. V. Morozov, D. Jiang, M. I. Katsnelson, I V. Grigorieva, S. V. Dubonos, and A. A. Firsov, "Two-dimensional gas of massless Dirac fermions in graphene." Nature, 438, 197 (2005).

22. X. Tian, C. Cheng, H. Yuan, J. Du, D. Xiao, S. Xie, and M. M. F. Choi, "Simultaneous determination of $L$-ascorbic acid, dopamine and uric acid with gold nanoparticles-cyclodextrin-graphene-modified electrode by square wave voltammetry." Talanta, 93, 79 (2012).

23. L. Chen, Y. Tang, K. Wang, C. Liu, and S. Luo, "Direct electrodeposition of reduced graphene oxide on glassy carbon electrode and its electrochemical application." Electrochem. Commun., 13, 133 (2011).

24. H. Chen, Z. Zhang, R. Cai, W. Rao, and F. Long, "Molecularly imprinted electrochemical sensor based on nickel nanoparticles-graphene nanocomposite modified electrode for determination of tetrabromobisphenol A." Electrochim. Acta 117, 385 (2014).

25. O. Metin, V. Mazumder, S. Ozkar, and S. Sun, "Monodisperse nickel nanoparticles and their catalysis in hydrolytic dehydrogenation of ammonia borane." $J$. Am. Chem. Soc., 231, 1468 (2010)

26. H. Kahri, V. Flaud, T. Ridha, and U. B. Demirci, "Aqueous hydrazine borane N2H4BH3 and nickel-based catalyst: an effective couple for the release of hydrogen in near-ambient conditions." J. Energy Inst., 91, 845 (2018).

27. S. Zhao, K. Zhang, Y. Bai, W. Yang, and C. Sun, "Glucose oxidase/colloidal gold nanoparticles immobilized in Nafion film on glassy carbon electrode: direct electron transfer and electrocatalysis." Bioelectrochemistry., 69, 158 (2006).

28. C. Xue, Q. Han, Y. Wang, J. Wu, T. Wen, R. Wang, J. Hong, X. Zhou, and H. Jiang, "Amperometric detection of dopamine in human serum by electrochemical sensor based on gold nanoparticles doped molecularly imprinted polymers." Biosens. Bioelectron., 49, 199 (2013).

29. J. Wang, B. Yang, J. Zhong, B. Yan, K. Zhang, C. Zhai, Y. Shiraishi, Y. Dua, and P. Yang, "Dopamine and uric acid electrochemical sensor based on a glassy carbon electrode modified with cubic Pd and reduced graphene oxide nanocomposite." J. Colloid. Interf. Sci., 497, 172 (2017).

30. Q. Yuan, Y. Liu, C. Ye, H. Sun, D. Dai, Q. Wei, G. Lai, T. Wu, A. Yu, L. Fu, and K. W. A Che, "Highly stable and regenerative graphene-diamond hybrid electrochemical biosensor for fouling target dopamine detection." Biosens. Bioelectron. 111, 117 (2018).

31. F. Gao, X. Cai, X. Wang, C. Gao, S. Liu, F. Gao, and Q. Wang, "Highly sensitive and selective detection of dopamine in the presence of ascorbic acid at graphene oxide modified electrode." Sens. Actuators B: Chem., 186, 380 (2018).

32. L. Yang, D. Liu, J. Huang, and T. You, "Simultaneous determination of dopamine, ascorbic acid and uric acid at electrochemically reduced graphene oxide modified electrode." Sens. Actuators B: Chem., 193, 166 (2014).

33. S. Liu, J. Yan, G. W. He, D. D. Zhong, J. X. Chen, L. Y. Shi, X. M. Zhou, and H. J. Jiang, "Layer-by-layer assembled multilayer films of reduced graphene oxide/ gold nanoparticles for the electrochemical detection of dopamine." J. Electroanal. Chem., 672, 40 (2012).

34. H. Teymourian, A. Salimi, and S. Khezrian, " $\mathrm{Fe}_{3} \mathrm{O}_{4}$ magnetic nanoparticles/reduced graphene oxide nanosheets as a novel electrochemical and bioeletrochemical sensing platform." Biosens. Bioelectron., 49, 1 (2013).

35. C. Wang, J. Du, H. Wang, C. Zou, F. Jiang, P. Yang, and Y. Du, "A facile electrochemical sensor based on reduced graphene oxide and $\mathrm{Au}$ nanoplates modified glassy carbon electrode for simultaneous detection of ascorbic acid, dopamine and uric acid." Sens. Actuators B: Chem., 204, 302 (2014).

36. Y. Ak, Y. Xue, Y. Zhang, X. Zhang, H. Zhao, X. Li, X. He, and Z. Yuan, "A simple one-pot synthesis of graphene nanosheet/ $\mathrm{SnO}_{2}$ nanoparticle hybrid nanocomposites and their application for selective and sensitive electrochemical detection of dopamine." J. Mater. Chem. B., 1, 1804 (2013).

37. J. M. Liu, X. X. Wang, M. L. Cui, L. P. Lin, S. L. Jiang SL, L. Jiao L, and L. H. Zhang, "A promising non-aggregation colorimetric sensor of AuNRs-Ag ${ }^{+}$for determination of dopamine." Sensor Actuat. B-Chem., 176, 97 (2013).

38. X. Liu, L. Cheng, J. Lei, and H. Ju, "Dopamine detection based on its quenching effect on the anodic electrochemiluminescence of CdSe quantum dots." Analyst, 133, 1161 (2008)

39. S. Govindaraju, S. Reddy Ankireddy, B. Viswanath, J. Kim, and K. Yun, "Fluorescent gold nanoclusters for selective detection of dopamine in cerebrospinal fluid." Sci. Rep., 7, 40298 (2017).

40. U Sivasankaran and K. G Kumar, "Electrochemical Sensing of Synthetic Antioxidant Propyl Gallate: A Cost Effective Strategy Using Nanoparticles.' J. Electrochem.Soc., 166, 92 (2019). 